Brazilian Journal
of Chemical
Engineering

\title{
NITROXIDE MEDIATED AND ATOM TRANSFER RADICAL GRAFT POLYMERIZATION OF ATACTIC POLYMERS ONTO SYNDIOTACTIC POLYSTYRENE
}

\author{
M. Abbasian ${ }^{1 *}$ and S. Esmaeily Shoja ${ }^{2}$ \\ ${ }^{1}$ Department of Basic Science, Payame Noor University, Phone: (+ 98) (411) (5492301), \\ Fax: (+ 98) (411) (5419744), PO Box 19395-3697, Tehran - Iran. \\ E-mail: m_abbasian20@yahoo.com,m_abbasian@pnu.ac.ir \\ ${ }^{2}$ Lab. of Materials, Faculty of Engineering, Islamic Azad University, Bonab branch, Bonab - Iran. \\ E-mail: esmaeily_aut@yahoo.com
}

(Submitted: August 10, 2011 ; Revised: October 3, 2011 ; Accepted: October 12, 2011)

\begin{abstract}
Living' radical graft polymerization was employed to prepare graft copolymers with nitroxidemediated arylated syndiotactic polystyrene as the backbone and polystyrene (PS), poly(p-methylstyrene) (PMS) and poly(methylmethacrylate) (PMMA) as branches. A two-stage process has been developed to synthesize the macroinitiator. First, syndiotactic polystyrene (sPS) was modified by the Friedel-Crafts reaction to introduce chlorine; second, the chlorine groups were converted to nitroxide mediated groups by coupling with 1-hydroxy-2,2,6,6-tetramethyl-1-piperidinyloxy (TEMPO-OH). The resulting macroinitiator (sPSTEMPO) for 'living' free radical polymerization was then heated in the presence of styrene and $p$ methylstyrene to form graft and block copolymers. We used the obtained copolymer and N-bromosuccinimide as brominating agent to achieve polymers with bromine groups. This brominated copolymer was used as a macroinitiator for polymerizing methyl methacrylate in the presence of the $\mathrm{CuBr} / \mathrm{bpy}$ catalyst system. The formation of the graft and block copolymers was confirmed by DSC, ${ }^{1} \mathrm{H}$ NMR and FTIR spectroscopy. This approach using macroinitiators is an effective method for the preparation of new materials.

Keywords: Syndiotactic polystyrene; Graft copolymer; Poly(methyl methacrylate); Atom transfer radical polymerization; Nitroxide-mediated 'living' free radical polymerization; TEMPO.
\end{abstract}

\section{INTRODUCTION}

Syndiotactic polystyrene (sPS) can be prepared by a homogeneous organometallic catalytic system based on a titanium compound and methylaluminoxane (MAO) (Ishihara et al., 1986)]Owing to its high melting point $\left(270^{\circ} \mathrm{C}\right)$, rapid crystallization rate, low density, excellent chemical resistance and enhanced mechanical properties, sPS has versatile applications in many fields, such as THE automotive, electronic and packaging industries. However, sPS is similar to atactic polystyrene in having poor impact and tear resistance and a low surface energy. The absence of polar groups in this polymer restricts its end uses, especially where adhesion to substrates and compatibility with polar polymers are desired. Therefore, modification of sPS is of interest.

In the past few years, there has been increased emphasis on applications of graft polymers, since they can combine the chemical and physical properties of two or more different monomers into a single polymeric chain. (Brownell et al., 2009; Nathinee Srinate et al., 2009; Endo et al., 2004; Mohajery et al., 2008; Can et al., 2010). In general,

*To whom correspondence should be addressed 
graft polymers can be synthesized by free radicalinduced grafting processes, which are the easiest and most widely accepted procedures for the preparation of these kinds of polymers.

Radical polymerization occupies an important position in commercial polymer production because of the scope of applicable monomers, the functional group tolerance, the wide range of reaction conditions, and the lower relative infrastructure costs. Unfortunately, these conventional reactions have significant limitations with respect to a chemist's ability to control the molecular weight distribution, molecular architecture, and composition of the polymers. In order to exact this control, several methodologies have been developed which reduce radical concentrations and efficiently exchange dormant chains with reactive radical species in order to minimize bimolecular termination reactions. The nature of the dormant chain differentiates these processes, with nitroxidemediated radical polymerization (NMP) (Hawker et al., 2001; Moad et al., 2008; Shoaeifar et al., 2007) exploiting the reversible cleavage of a nitroxide - carbon bond, thiocarbamates supporting a reversible addition - fragmentation chain transfer (RAFT) [Moad et al. (2005)] pathway, and ruthenium and copper complexes mediating the exchange of halogen-capped polymer chains through an atom transfer radical polymerization (ATRP) (Matyjaszewski and Xia, 2001; Ouchi et al., 2008; Abbasian et al., 2006; Gheybi et al., 2007; Schellenberg, 2009; Srinate et al., 2009; Abbasian et al., 2007). Together, these processes are termed controlled radical polymerization (CRP) and provide extraordinary control over polymer molecular weight and molecular weight distributions. Great interest has been placed on the development of CRP mediated by transition metals due to the inherent tunability of metal complexes through alteration of the ligand framework and the flexibility of metal oxidation states in supporting one-electron transformations (di Lena and Matyjaszewski, 2009; Poli and Eur, 2011).

Graft copolymerization of vinyl monomers onto plastics in homogeneous media is one way to modify and enlarge the range of useful plastics. Compared with other graft copolymerizations such as anionic polymerization, an advantage of 'living' free radical polymerization (LFRP) is that, in the preparation of grafted copolymers, the terminal groups are stable in air at room temperature, and prepolymers can be isolated, stored, and used as needed. Moreover, in anionic polymerization, stringent polymerization conditions are required (Kaneko et al., 2006).
Therefore, functionalization or grafting a polar group onto the sPS backbone seems to be a desirable way to solve the problem of having poor impact and tear resistance and a low surface energy. So far, several attempts have been made to prepare functionalized and grafted sPS in our laboratory and other laboratories. These attempts include sulfonated sPS, maleic-anhydride grafted sPS, hydroxylated sPS and arylated sPS (Li et al., 2001; Zinck et al., 2009; Lim et al., 2002; Li et al., 2002; Liu and Sen, 2000; Gao et $a l ., 2005)$. The present work is designed to synthesize graft (sPS-g-PS) and block [sPS-g-(PS-b-PMS)] copolymers onto sPS by utilizing the NMRP of styrene and p-methylstyrene monomers by TEMPO initiator from nitroxide mediated sPS macroinitiator and the ATRP of methacrylate monomers after bromination of the obtained graft copolymer. The $\alpha$-ph-ch-sPS macroinitiator was prepared from the acid-catalyzed halogenation reaction of sPS, which was synthesized in a heterogeneous process with a-phenyl chloroacetyl chloride and anhydrous aluminum chloride in carbon disulfide via a FriedelCrafts acylation reaction.

\section{EXPERIMENTAL}

\section{Materials}

Syndiotactic polystyrene and TEMPO were prepared by the method reported previously by our research group (Rahmani et al., 2007; Bani et al., 2004). Styrene (Tabriz Petrochemical Co., Iran), p-methylstyrene and methyl methacrylate (Merck) were distilled under reduced pressure from $\mathrm{CaH}_{2}$ before use. Toluene and THF (Merck) were dried by refluxing over sodium and distilled under argon prior to use. N-bromosuccinimide (NBS) from Merck was purified by recrystalization in water at $70^{\circ} \mathrm{C}$. 2,2'-azobis(isobutyronitrile) (AIBN) from Aldrich, were recrystallized in ethanol at $50^{\circ} \mathrm{C}$. Sodium L-(+)-ascorbate was obtained from Merck and used without purification. Aluminum trichloride was purchased from Aldrich. All other reagents were purchased from Merck and purified according to the standard methods.

\section{Instrumentation}

FTIR spectra were obtained on a Shimadzu $8101 \mathrm{M}$ FT-IR. The samples were prepared by grinding the dry powders with $\mathrm{KBr}$ and compressing the mixture to form disks. The disks were stored in a desicator to avoid moisture absorption. Spectra were 
recorded at room temperature. ${ }^{1} \mathrm{H}$ NMR spectra were obtained at $25^{\circ} \mathrm{C}$ on a Brucker FT-NMR $(400 \mathrm{MHz})$ spectrometer. Sample for ${ }^{1} \mathrm{H}$ NMR spectroscopy was prepared by dissolving about $10 \mathrm{mg}$ of product in $5 \mathrm{ml}$ of deuterated chloroform. DSC analyses were carried out using a NETZSCH (Germany) - DSC 200 F3 Maia. The sample was first heated to $200^{\circ} \mathrm{C}$ and kept for $5 \mathrm{~min}$ to eliminate the heat history. The sample was then cooled down at a rate of $10^{\circ} \mathrm{C} / \mathrm{min}$. Then the sample was reheated to $200^{\circ} \mathrm{C}$ at a rate of $10^{\circ} \mathrm{C} / \mathrm{min}$. The entire test was performed under

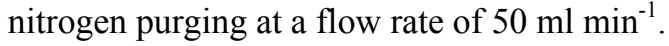

\section{Synthesis of Acetylated Syndiotactic Polystyrene}

Friedel-Crafts acylation was performed in a heterogeneous process, according to Scheme 1. Thus, $0.6 \mathrm{~g}$ of sPS, prepared previously, was suspended in $40 \mathrm{~mL}$ of $\mathrm{CS}_{2}$ in a two-necked, round-bottom flask fitted with a condenser and a $\mathrm{CaCl}_{2}$ guard tube. The reaction system was maintained at a temperature of $20^{\circ} \mathrm{C}$ and stirred vigorously with a magnetic pellet.

Then $2.0 \mathrm{~g}$ of $\mathrm{AlCl}_{3}(0.015 \mathrm{~mol})$ was added rapidly. After the mixture turned orange-red, $2.2 \mathrm{ml}$ $(0.015 \mathrm{~mol})$ of $\alpha$-phenyl chloroacetyl chloride was added through a dropping funnel after dilution with $20 \mathrm{~mL} \mathrm{CS}$. The reaction was conducted at a temperature of $20^{\circ} \mathrm{C}$ for 3 hours and then terminated by the addition of ice water followed by concentrated hydrochloric acid. The polymer was filtered, washed several times with distilled water, and dried under vacuum at temperature $70^{\circ} \mathrm{C}$.

Yield: $1.05 \mathrm{~g}$ (white powder) (30\%).

FTIR (KBr, cm ${ }^{-1} \mathrm{OK}$ ): 3053 (phenyl protons of $\alpha$-phenyl-chloroacetyl chloride and sPS), 2951 (aliphatic protons of a-phenyl-chloroacetyl chloride and sPS), 1729 (-CO- group of $\alpha$-phenylchloroacetyl chloride), 1311 (-PhCHCl- groups of $\alpha$-phenylchloroacetyl chloride).

\section{Preparation of sPS -TEMPO}

In a two-neck round-bottom flask equipped with condenser, dropping funnel, gas inlet/outlet, and a magnetic stirrer, $0.051 \mathrm{~g}(0.33 \mathrm{mmol})$ of TEMPO$\mathrm{OH}$ that was synthesized by our research group previously (Shoaeifar et al., 2007) was dissolved in anhydrous N,N-dimethylformamide (DMF) $(1 \mathrm{ml})$ and added under $\mathrm{N}_{2}$ atmosphere to $8.0 \mathrm{mg}(0.33 \mathrm{mmol})$ of hexane-washed $\mathrm{NaH}$ (from $60 \%$ suspension in oil). The mixture was stirred for 30 minutes, and then $1 \mathrm{~g}$ of $\alpha$-Phenyl-chloroacetylation of sPS was added under $\mathrm{N}_{2}$ and refluxed for 24 hours. The reaction was terminated by pouring the content of the flask into a large amount of acidic methanol. The white solid was filtered and dried in vacuum $(1.1 \mathrm{~g})(70 \%)$.

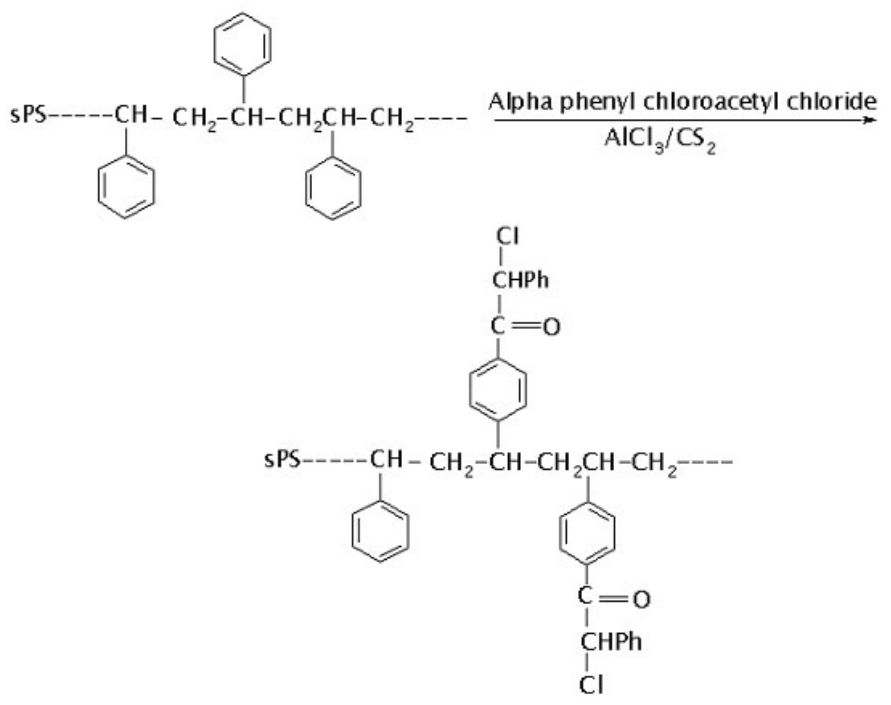

Scheme 1: Friedel-Crafts acylation of syndiotactic polystyrene 


\section{Living Radical Graft and Block Polymerization of Styrene and p-Methylstyrene Onto Syndiotactic Polystyrene}

$0.4 \mathrm{~g}$ of the macroinitiator (sPS-TEMPO) and $5 \mathrm{ml}$ $(0.043 \mathrm{mmol})$ of styrene or p-methyl styrene were placed in an ampoule (20 cm in diameter), degassed with several freeze-pump-thaw cycles, sealed off under vacuum and placed in an oil bath. The solution was stirred by using an orbital shaker and heated at $125^{\circ} \mathrm{C}$. During the reaction, the viscosity of the solution was observed to gradually increase. After 14 hours, the solution was dissolved in $10 \mathrm{~mL}$ of $\mathrm{CH}_{2} \mathrm{Cl}_{2}$ and precipitated in $50 \mathrm{ml}$ of hexane for 24 hours and reprecipitated from $\mathrm{CH}_{2} \mathrm{Cl}_{2}$ into $50 \mathrm{~mL}$ of methanol. The crude product was dried in vacuum and weighed (yield: $80 \%$ ). The crude product was extracted with cyclohexane at $30^{\circ} \mathrm{C}$ three times in order to remove ungrafted atactic polystyrene. Residual atactic homopolystyrene could not be observed. The purified product was dried in vacuum and weighed (Scheme 2). Yield: $0.79 \mathrm{~g}$ (16\%)

\section{Bromination of sPS-g-(PS-b-PMS)}

N-bromosuccinimide (NBS, $0.2 \mathrm{~g}$ ) and AIBN $(0.03 \mathrm{~g})$ were added to a suspension of syndiotactic
sPS-g-(PS-b-PMS) $(1 \mathrm{~g})$ in $\mathrm{CCl}_{4}(40 \mathrm{~mL})$ in a $100 \mathrm{~mL}$ round bottomed flask with a magnetic stirring bar. After refluxing at $70^{\circ} \mathrm{C}$ for $5 \mathrm{~h}$, the reaction mixture was filtered, washed well with acetone and then dried overnight under vacuum for $24 \mathrm{~h}$. Yield: $1.09 \mathrm{~g}$.

\section{Preparation of [sPS-g- (PS-b-PMS)]-g-PMMA}

In a typical experiment, a dry round-bottomed flask fitted with a magnetic stirring bar was charged with anisole $(15 \mathrm{~mL}), \mathrm{CuBr}(0.07 \mathrm{~g}, 0.48 \mathrm{mmol})$, bpy (0.15 g, $0.96 \mathrm{mmol})$, MMA ( $3 \mathrm{~mL}, 28 \mathrm{mmol})$, and brominated sPS-g-(PS-b-PMS) $(0.2 \mathrm{~g})$. The flask was sealed and three cycles of freeze-pumpthaw were performed to remove oxygen. Then the flask was filled with purified nitrogen and the reaction mixture was heated at $90^{\circ} \mathrm{C}$ for $10 \mathrm{~h}$ with stirring. The reaction was terminated by pouring the contents of the flask into a large amount of acidic methanol. The precipitated polymer was filtered, washed several times, and dried under vacuum (Scheme 3).

The powder obtained was extracted with cyclohexane at $30^{\circ} \mathrm{C}$ three times to remove poly(methyl methacrylate) homopolymers. We observed no homopolymers in this condition.

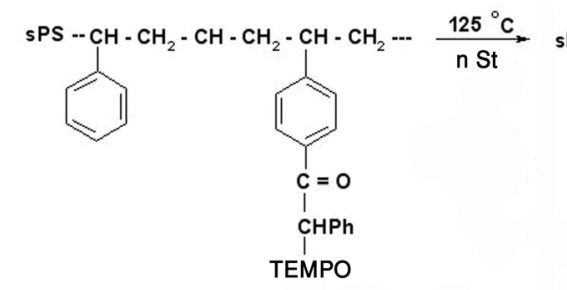

(a)

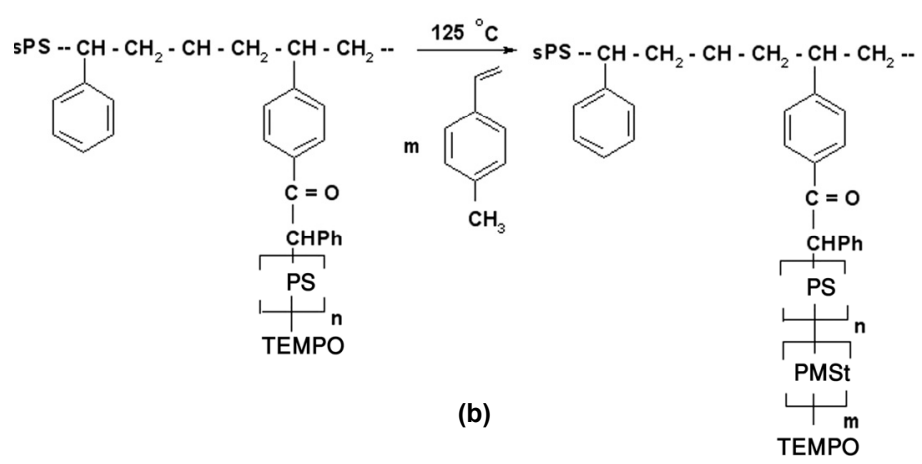

Scheme 2: Living radical graft and block polymerization of styrene (a) and p-methylstyrene onto syndiotactic polystyrene (b) 


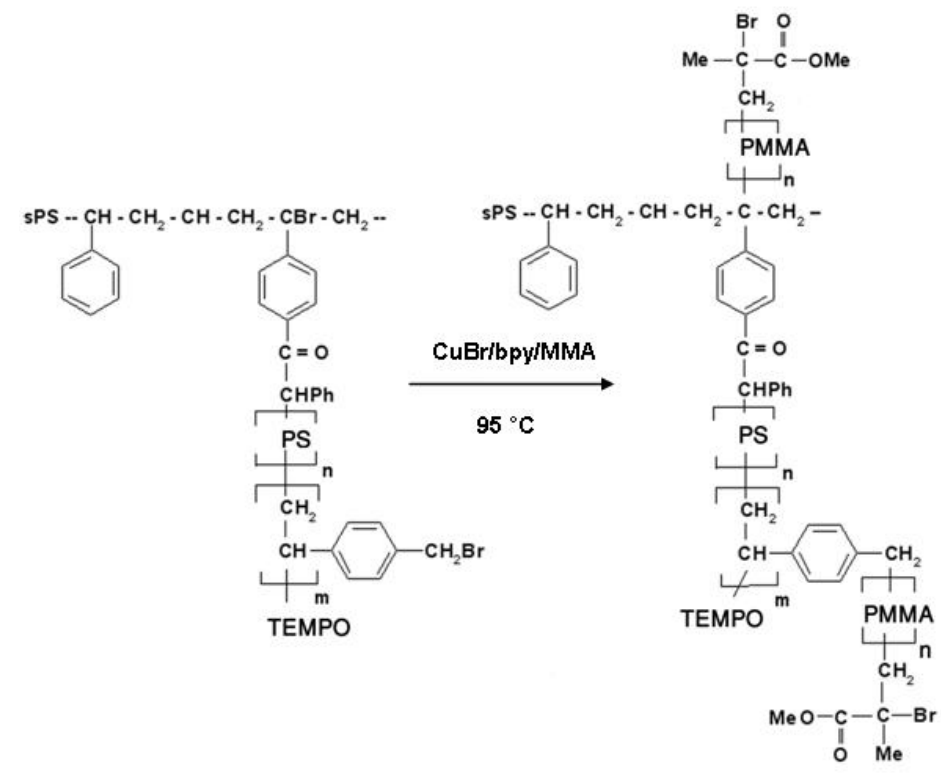

Scheme 3: Preparation of [sPS-g- (PS-b-PMS)]-g-PMMA

\section{RESULTS AND DISCUSSION}

In our previous work, we reported an efficient procedure for the preparation of acetylated SPS in a heterogeneous process through the Friedel-Crafts acetylation reaction and an efficient procedure for the synthesis of controlled graft onto sPS by the atom transfer radical polymerization (ATRP) method (Abbasian et al., 2007). Powdered sPS was partially acetylated using $\alpha$-phenyl chloroacetyl chloride as the acetylating agent and anhydrous aluminum chloride as the catalyst in carbon disulfide. The final product of chloroacetylation reaction is an aromatic ketone. Following this procedure, controlled graft and block copolymers were synthesized by ATRP and NMRP techniques.

\section{Synthesis of Graft Copolymer Onto Syndiotactic Polystyrene}

In order to produce the active sites on syndiotactic polystyrene, TEMPO was added to sPS. After the alpha chloro acetylation of syndiotactic polystyrene, OH-TEMPO reacts with $\alpha$-ph-ch-sPS to give the macroinitiator sPS-TEMPO. In accord to our previous work (Abbasian et al., 2007), it was observed that no cross-linking reaction took place under this condition, because we added TEMPO-OH under mild and controlled condition. The anion of TEMPO was prepared and then chloroarylated sPS was added to the medium under controlled conditions. Comparison of the ${ }^{1} \mathrm{H}-\mathrm{NMR}$ spectrum of $\alpha$-ph-ch-sPS with the ${ }^{1} \mathrm{H}-\mathrm{NMR}$ spectrum of sPS-TEMPO indicates that, during the reaction, because the chemical shift of $\mathrm{CH}-\mathrm{O}$ and $\mathrm{CH}-\mathrm{Cl}$ are similar, there are no changes in the chemical shifts due to the formation of $\mathrm{CH}-\mathrm{O}$, whereas the functional group of TEMPO appears with characteristic signals at $0.5-1.58 \mathrm{ppm}$ (Figure 1).

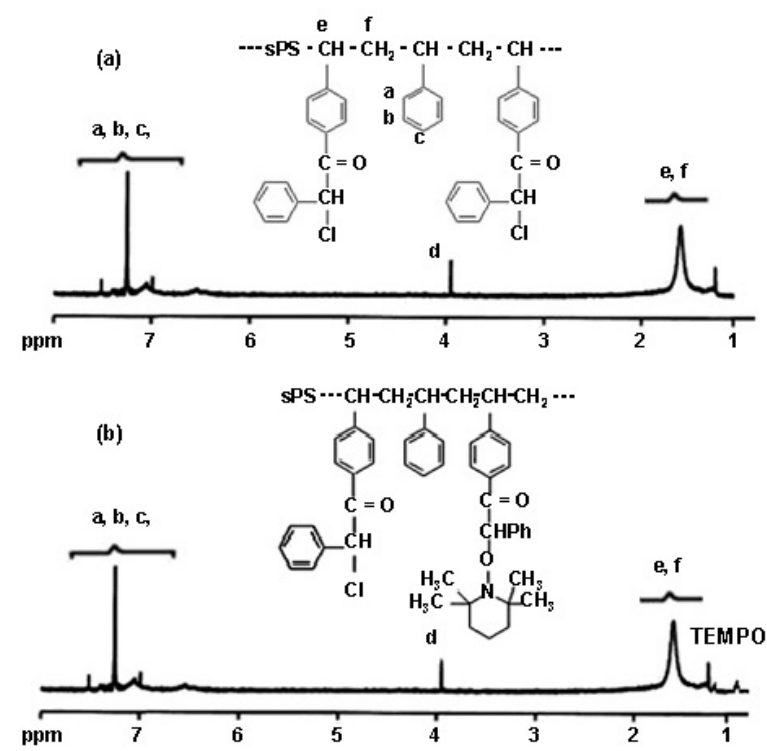

Figure 1: ${ }^{1} \mathrm{H}$ NMR spectrum of $\alpha$-ph-ch-sPS (a) and the macroinitiator sPS-TEMPO (b) 
The FTIR spectrum of the macroinitiator sPSTEMPO demonstrates an absorption band at $1480 \mathrm{~cm}^{-1}$ which is attributed to the methyl band of TEMPO. The "C-N" and "N-O" stretching bands of TEMPO are not resolved in FTIR spectrum of the macroinitiator because these peaks overlap with the peaks of sPS (Figure 2 (a)).

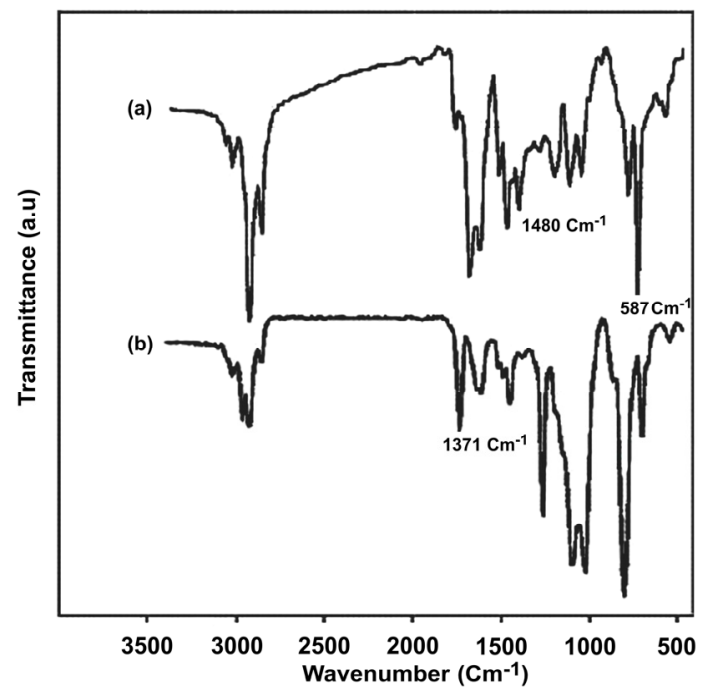

Figure 2: FTIR spectrum of the macroinitiator sPSTEMPO (a) and the FTIR spectrum of [sPS-g- (PSb-PMS)]-g-PMMA (b)

The thermal hemolytic scission of the $\mathrm{C}-\mathrm{O}$ bond of the aminoxy moiety of sPS-TEMPO takes place at $125^{\circ} \mathrm{C}$ and causes the radical polymerization of styrene and p-methylstyrene to yield the graft (sPS-g-PS) and block [sPS-g-(PS-b-PMS)] copolymers. The bond dissociation is considered to be reversible. The crude polymerization product was purified as described in the experimental section.

To successfully carry out this polymerization, it was necessary to show that at this reaction temperature no spontaneous thermal polymerization occurred and that, in this reaction condition, the polymerization is living. For comparison, a blank experiment was done in the absence of TEMPO on Syndiotactic polystyrene. In this condition, no homo polystyrene or poly(p-methyl styrene) were formed in the absence of the macroinitiator under identical NMRP conditions. This suggests that the formation of homopolymer in the grafting reaction can be excluded and that the polymerization is living. ${ }^{1} \mathrm{H}$ NMR spectra of the purified products (Figure 3) indicate the formation of graft and block copolymers, since the chemical shifts at $6.39-7.25 \mathrm{ppm}$ represent the aromatic protons in polystyrene and those at 1.2-2.1 ppm represent the aliphatic protons in polystyrene. Since the ratio of aliphatic hydrogens to aromatic hydrogens is 3 to 5 , there is an increase in the integration intensity of the aromatic hydrogens in the ${ }^{1} \mathrm{H}$ NMR spectrum.

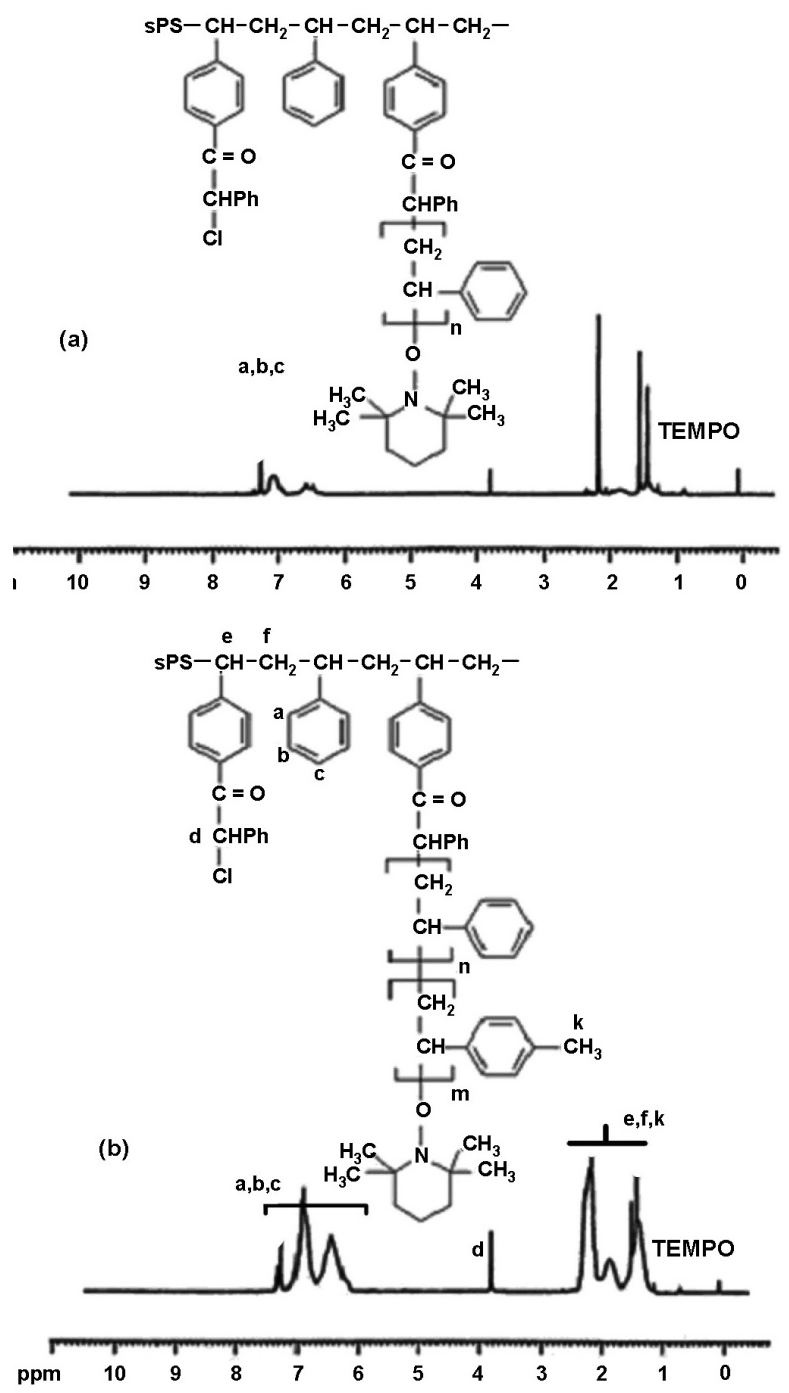

Figure 3: ${ }^{1} \mathrm{H}$ NMR spectra of sPS-g-PS (a); sPS-g(PS-b-PMS) (b)

\section{Bromination of sPS-g-(PS-b-PMS)}

We used sPS-g-(PS-b-PMS) as the starting polymer and N-boromosuccinimide as the brominating agent to obtain polymers with a bromine group. N-Boromosuccinimide is usually used for the introduction of bromine into allylic or benzylic positions (Pizey, 1974). Thus, both the methyl groups and backbone methane carbons can be brominated in 
sPS-g-(PS-b-PMS). The ${ }^{1} \mathrm{H}$ NMR spectrum of brominated sPS-g-(PS-b-PMS) confirms the bromination of methyl and methine groups since the chemical shifts at $4.65-4.79 \mathrm{ppm}$ represent the $-\mathrm{CHBr}$ protons in the brominated polymer. There are no changes in the chemical shift of $-\mathrm{CHPhCl}$ (which is related to $\alpha$-ph-ch-sPS not coupled with TEMPO), whereas the integration intensity of the aliphatic hydrogens decreases. The ${ }^{1} \mathrm{H}$ NMR spectra showed that the functional groups of TEMPO were retained at the end of the polymer chains, providing strong evidence for the NMRP reaction occurring (Figure 4 (a)).

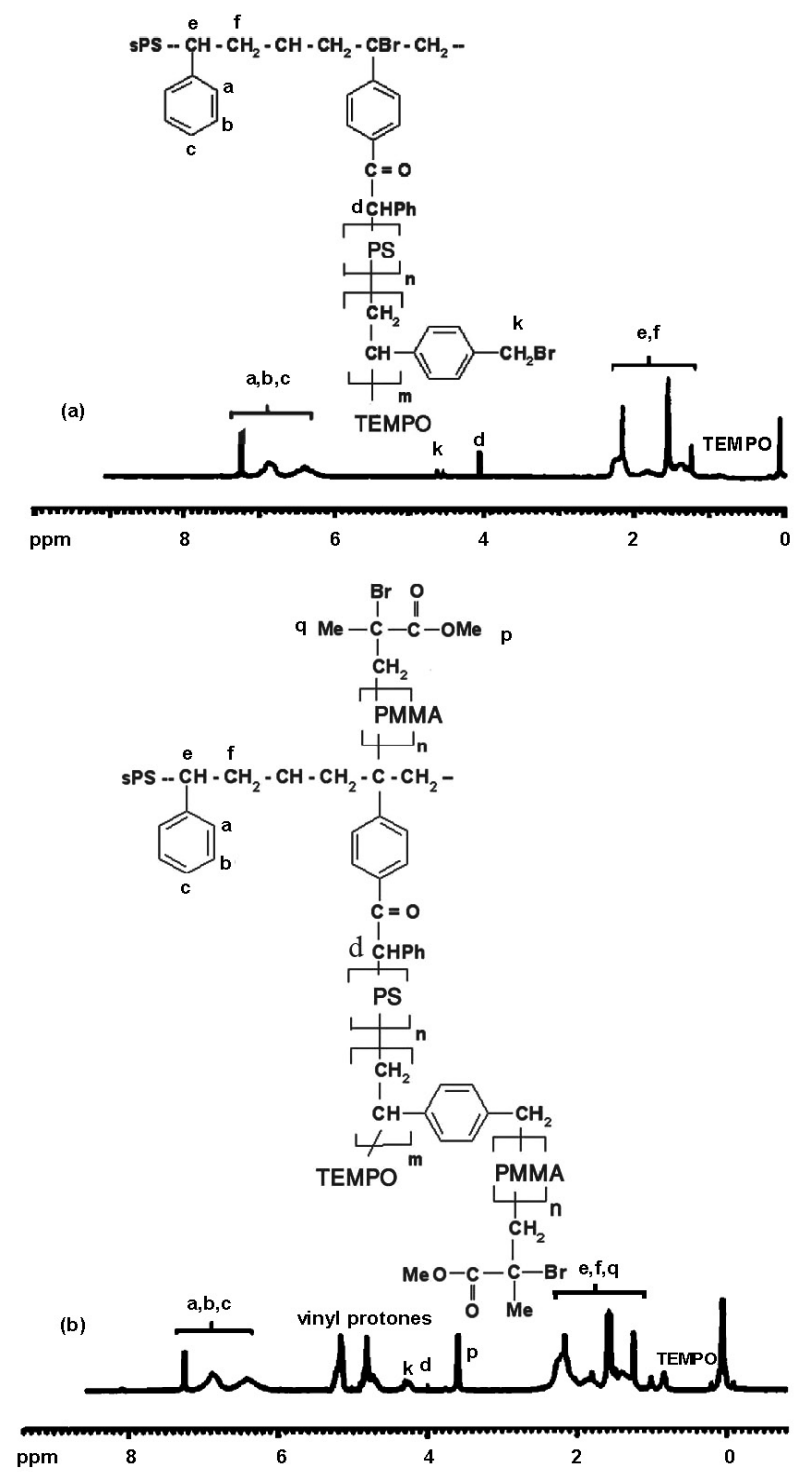

Figure 4: ${ }^{1} \mathrm{H}$ NMR spectra of sPS-g-(PS-b-PMS)-Br (a) and ${ }^{1} \mathrm{H}$ NMR Spectra of [sPS-g- (PS-b-PMS)]-gPMMA (b)

\section{Preparation of [sPS-g- (PS-b-PMS)]-g-PMMA}

The synthesis of graft copolymers can be accomplished through one of the three following routes: (I) "grafting from" reactions (utilizing polymerization of grafts from a macroinitiator with pendant functionality), (II) "grafting through" processes (by homo - or copolymerization of a macromonomer) and (III) "grafting onto" (occurring when the growing chain is attached to a polymer backbone). The first two methods have been used in conjunction with ATRP in the design of graft copolymers and underscore the versatility of this controlled radical polymerization technique to synthesize a variety of copolymers. The graft copolymerization of methyl methacrylate initiated by sPS-g-(PS-b-PMS)-Br as macroinitiator in the presence of the $\mathrm{CuBr} / \mathrm{bpy}$ catalyst system was first studied in anisole solvent to solubilize the catalyst and also brominated sPS-g-(PS-b-PMS) at $90^{\circ} \mathrm{C}$.

The FTIR and ${ }^{1} \mathrm{H}$ NMR spectrum of the purified product (Figure 2(b) and Figure 4(b)) indicates the formation of graft copolymer [sPS-g- (PS-b-PMS)]g-PMMA. In the FTIR, the spectrum of the graft copolymer displays a typical carbonyl stretch $\left(1731 \mathrm{~cm}^{-1}\right)$, which is related to the carbonyl groups of the PMMA segments (Figure 2 (b)).

It is obvious that the peak at $587 \mathrm{~cm}^{-1}$ could be attributed to $-\mathrm{CBrMe}$ at the end of PMMA and indicates that the polymerization is living (Janata et al., 2001).

The ${ }^{1} \mathrm{H}$ NMR spectra of [sPS-g- (PS-b-PMS)]-gPMMA is illustrated in Figure 4(b). The ${ }^{1} \mathrm{H}$ NMR spectrum of [sPS-g- (PS-b-PMS)]-g-PMMA displays a characteristic peak at $\delta=3.61 \mathrm{ppm}$, which is related to the $-\mathrm{OCH}_{3}$ groups of the PMMA segments, and a peak at $\delta=0.8-1.1 \mathrm{ppm}$, which is related to the $-\mathrm{CH}_{3}$ groups of the PMMA and a peak at $\delta=4.65-$ $5.15 \mathrm{ppm}$, which is related to the vinyl protons that form at the end of chain polymers.

\section{Thermal Properties Analysis}

In this work, DSC was employed to investigate the thermal properties of pure sPS and modified sPS. The DSC curves of pure sPS and grafted onto syndiotactic polystyrene are shown in Figure 5. For pure sPS, $T_{m}$ and $\mathrm{T}_{\mathrm{c}}$ are around 270 and $240^{\circ} \mathrm{C}$, respectively, similar to the values previously obtained (Matyjaszewski and Xia, 2001; Srinate et al., 2009; Malanga, 2000). In the case of acetylated syndiotactic polystyrene, no peaks were seen, which indicated that the acetylated syndiotactic polystyrene was unable to crystallize due to the large size of the substituent group. Therefore, it 
is reasonable to assume that the acetylated syndiotactic polystyrene unit exists only in the amorphous region. The non-crystallizable acetylated units can interrupt or terminate crystal growth along the polymer chain (Gao and $\mathrm{Li}, 2004)$. Interestingly, the glass transition temperature $\left(\mathrm{T}_{\mathrm{g}}\right)$ of syndiotactic polystyrene was found to be $98.4^{\circ} \mathrm{C}$. A similar phenomenon was observed with branched oligoethene grafted sPS, as reported by Liu and Sen (2001). For the sPS-g-(PS-b-PMS) and [sPS-g- (PS-b-PMS)]-g-PMMA copolymers, as expected, no $T_{m}$ and $T_{c}$ are detected, regardless of the degree of graft, which indicates that these samples are unable to crystallize. This result is quite in agreement with that for the sPS-graft-aPS copolymers prepared by combining the metallocene polymerization technique with the marcomonomer method, as reported by Senoo et al. (2001). It was found that the grafted copolymers with lower content of aPS side chains could crystallize from the melt, while that with higher content of aPS was in an amorphous state. The effect of the graft chains on the crystallinity was discussed in terms of the friction force for reptation and the cohesive power. On the other hand, the $T_{g}$ values of our graft copolymers differ slightly in comparison to the neat polymer. For example, the $\mathrm{T}_{\mathrm{g}}$ of pure sPS is $99.4^{\circ} \mathrm{C}$, while $\mathrm{T}_{\mathrm{g}}$ of sPSg-(PS-b-PMS) and [sPS-g- (PS-b-PMS)]-g-PMMA were found to be $99.2^{\circ} \mathrm{C}$ and $100.7^{\circ} \mathrm{C}$, respectively.

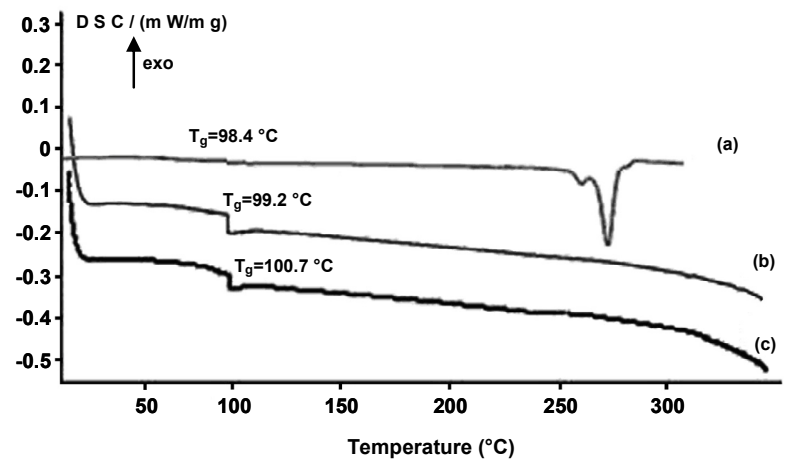

Figure 5: DSC traces of neat sPS (a), sPS-g-(PS-bPMS) (b) and [sPS-g- (PS-b-PMS)]-g-PMMA (c)

\section{CONCLUSION}

We have described the efficient synthesis of a sPS graft copolymer, [sPS-g- (PS-b-PMS)]-g-PMMA, by the ATRP and NMRP technique. Syndiotactic polystyrene (sPS) was functionalized in the side phenyl rings with $\alpha$-phenyl chloroacetyl ( $\alpha$-ph-ch) groups using the Friedel-Crafts reaction; the chloro groups were then converted to nitroxide mediated groups by coupling with 1-hydroxy-2,2,6,6-tetramethyl-1-piperidinyloxy (TEMPO-OH). The resulting macro-initiator (sPSTEMPO) for 'living' free radical polymerization was then heated in the presence of styrene and p-methylstyrene to form graft and block copolymers. We used sPS-g-(PS-b-PMS) as the starting polymer and $\mathrm{N}$-bromosuccinimide as the brominating agent to obtain copolymers with a bromine group. This macroinitiator can polymerize methylmethacrylate monomers in the presence of the $\mathrm{CuBr} / \mathrm{bpy}$ catalyst system at $90^{\circ} \mathrm{C}$. This method of preparation of sPS graft copolymers is attractive because of the relatively wide scope of monomers that can be employed, the stability of the catalyst, the simple polymerization procedure, and the good control of graft structure. These structures were determined by ${ }^{1} \mathrm{H}$ NMR, DSC and FT IR spectroscopy.

\section{ACKNOWLEDGMENT}

The authors express their gratitude to the Bonyade Melli Nokhbeghan Institute and Payame Noor University for supporting of this project.

\section{NOMENCLATURE}

\begin{tabular}{|c|c|}
\hline ATRP & $\begin{array}{l}\text { Atom transfer radical } \\
\text { polymerization }\end{array}$ \\
\hline NMRP & $\begin{array}{l}\text { Nitroxide mediated radical } \\
\text { polymerization }\end{array}$ \\
\hline PS & Polystyrene \\
\hline sPS & Syndiotactic Polystyrene \\
\hline aPS e & Atactic Polystyren \\
\hline PMS & Poly(p-methylstyrene) \\
\hline PMMA & Poly(methyl methacrylate) \\
\hline TEMPO & $\begin{array}{l}\text { 2,2,6,6-tetramethyl-1- } \\
\text { piperidinyloxy }\end{array}$ \\
\hline DSC & $\begin{array}{l}\text { Differential scanning } \\
\text { calorimetry }\end{array}$ \\
\hline TEMPO-OH & 4-hydroxy TEMPO \\
\hline$\alpha$-ph-ch-sPS & $\begin{array}{l}\text { Alpha phenyl chloroacetylated } \\
\text { syndiotactic polystyrene }\end{array}$ \\
\hline LFRP & $\begin{array}{l}\text { Living free radical } \\
\text { polymerization }\end{array}$ \\
\hline
\end{tabular}

\section{REFERENCES}

Abbasian, M., Rahmani, S., Mohammadi, R., Entezami, A., Graft copolymerization of styrene or methyl methacrylate onto syndiotactic polystyrene by ATRP technique. J. Appl. Polym. Sci., 104, 611 (2007). 
Bani, F., Abbasian, M., Afshar Taromi, F., Entezami, A., Polystyrene grafted to ABS backbone by living radical polymerization with TEMPO. Iran Polym. J., 13, 513 (2004).

Brownell, L. V., Shin, J., Bae, C., Synthesis of polar block grafted syndiotactic polystyrenes via a combination of iridium-catalyzed activation of aromatic $\mathrm{C}-\mathrm{H}$ bonds and atom transfer radical polymerization. Journal of Polymer Science Part A: Polymer Chemistry 47, 6655 (2009).

Can, A., Altuntas, E., Hoogenboom, R., Schubert, U., Synthesis and MALDI-TOF-MS of PS-PMA and PMA-PS block copolymers. European Polymer Journal, 46, 1932 (2010).

di Lena, F., Matyjaszewski, K., Transition metal catalysts for controlled radical polymerization. Prog. Polym. Sci., 35, 959-1021 (2010).

Endo, K., Tomoaki, S., Synthesis of graft copolymer from copolymerization of styrene-terminated poly(ethylene oxide) macromonomer and styrene with $\mathrm{CpTiCl} 3$ /methylaluminoxane catalyst. Journal of Polymer Science Part A: Polymer Chemistry, 42, 2904 (2004).

Gheybi, H., Abbasian, M., Najafi Moghaddam, P., Entezami, A., Chemical modification of polyaniline by N-grafting of polystyrene synthesized via ATRP. J. Appl. Polym. Sci., 106, 3495 (2007).

Gao, Y., Li, H. M., Synthesis and characterization of acetylated syndiotactic polystyrene. Polym. Int., 53, 1436 (2004).

Gao, Y., Li, S., Li, H., Wang, X., Synthesis of syndiotactic-polystyrene-graft-poly(methyl methacrylate) and syndiotactic-polystyrene-graftatactic-polystyrene by atom transfer radical polymerization. Eur. Polym. J., 41, 2329-2334 (2005).

Hawker, C. J., Bosman, A. W., Harth, E., Catalytic chain transfer in free-radical polymerizations. Chem. Rev., 101, 3661-3688 (2001).

Ishihara, N., Seimiya, T., Kuramoto, M., Uoi, M., Crystalline syndiotactic polystyrene. Macromolecules, 19, 246 4, (1986).

Janata, M., Masar, B., Toman, L., Vlcek, P., Policka, P., Brus, J., Holler, P., Multifunctional ARTP macroinitiators for the synthesis of graft copolymers. React. Funct. Polym., 50, 67 (2001).

Kaneko, F., Uda, Y., Kajiwara, A., Tanigaki, N., Molecular-complex formation of syndiotactic polystyrene with stable radical molecules. Macromolecular Rapid Communications, 27, 1643 (2006).

Li, H. M., Liu, J. C., Zhu, F. M., Lin, S. A., Synthesis and physical properties of sulfonated syndiotactic polystyrene ionomers. Polym. Int., 50, 421 (2001).
Li, H. M, Shen, Z. G., Zhu, F. M., Lin, S. A., Polymer blends of sPS/PA6 compatibilized by sulfonated syndiotactic polystyrene. Eur. Polym. J., 38, 1255-1263 (2002).

Lim, J. G., Baik, J. H., Zhang, X. Q., Son, Y. G., Choi, W., Mand Park, O., A novel preparation method of maleic anhydride grafted syndiotactic polystyrene and its blend performance with nylon6. Polym. Bull., 48, 397 (2002).

Liu, S., Sen, K., Syntheses of syndiotactic-Polystyrenegraft-poly(methyl methacrylate), syndiotacticpolystyrene-graft-poly(methyl acrylate), and syndiotactic-polystyrene-graft-atactic-polystyrene with defined structures by atom transfer radical polymerization. Macromolecules, 33, 5106 (2000).

Liu, S., Sen, A., Grafting of syndiotactic polystyrene by branched oligoethene using [ $\mathrm{Ni}(\pi$-methallyl) $(\mathrm{Br})]_{2} / \mathrm{AlCl}_{3}$ catalyst. J. Polym. Sci. A: Polym. Chem., 39, 446 (2001).

Moad, G., Rizzardo, E., Thang, S. H., Toward living radical polymerization. Acc. Chem. Res., 41, 11331142 (2008).

Moad, G., Rizzardo, E., Thang, S. H., Living radical polymerization by the RAFT process. Aust. J. Chem., 58, 379-410 (2005).

Matyjaszewski, K., Xia, Atom transfer radical polymerization. J. Chem. Rev., 101, 2921-2990 (2001).

Malanga, M., Syndiotactic Polystyrene Materials. Adv. Mater., 12, 1869 (2000).

Nathinee Srinate, N., Supakanok Thongyai, S., Piyasan Praserthdam, P., Synthesis and characterization of graft copolymers of syndiotactic polystyrene with polybutadiene and 4-methylstyrene. Journal of Applied Polymer Science, 112, 335 (2009).

Ouchi, M., Terashima, T., Sawamoto, M., Precision control of radical polymerization via transition metal catalysis: from dormant species to designed catalysts for precision functional polymers. Acc. Chem. Res., 41, 1120-1132 (2008).

Poli, R., Radical coordination chemistry and its relevance to metal-mediated radical polymerization. Eur. J. Inorg. Chem., 1513-1530 (2011).

Pizey, J. S., Synthesis Reagents. Vol. II, Ellis Horwood Limited, Chichester (1974).

Rahmani, S., Abbasian, M., Najafi Moghaddam, P., Entezami, A., Investigation of styrene/1hexene copolymerization by homogeneous and heterogeneous bisindenyl ethane zirconium dichloride catalyst system. J. Appl. Polym. Sci., 104, 4008 (2007).

Shabnam Mohajery, S., Sohrab Rahmani, S., Entezami, A., Synthesis of functional polyethylene graft copolymers by nitroxide-mediated living 
radical polymerization. Polymers for Advanced Technologies, 19, 1528 (2008).

Shoaeifar, P., Abbasian, M., Entezami, A., A convenient method for preparation of amphiphilic monomethoxypoly (ethylene glycol)ypolystyrene diblock copolymer by NMRP technique. J. Polym. Res., 14, 45 (2007).

Schellenberg, J., Functionalization and block/graft reactions of syndiotactic polystyrene using borane comonomers and chain transfer agents syndiotactic polystyrene, synthesis, characterization. Processing and Applications, 395 (2009).

Senoo, K., Endo, K., Tosaka, M., Murakami, S., Kohjiya, S., Polymorphic behavior of syndiotactic polystyrene-based graft copolymers with polystyrene and polyisoprene side chains, Macromolecules, 34, 1267 (2001).

Zinck, P., Bonnet, F., Mortreux, A., Visseaux, M., Functionalization of syndiotactic polystyrene. Progress in Polymer Science, 34, 4, 369-392 (2009). 